Case Reports
in Dermatology
Case Rep Dermatol 2021;13:121-128

DOI: 10.1159/000511984

Published online: February 16, 2021

(C) 2021 The Author(s)

Published by S. Karger AG, Basel

www.karger.com/cde

This article is licensed under the Creative Commons Attribution-NonCommercial 4.0 International License (CC BY-NC) (http://www.karger.com/Services/OpenAccessLicense). Usage and distribution for commercial purposes requires written permission.

\title{
Subtype-Specific Off-Label Treatment of Rosacea
}

\author{
Nita Wienholtz ${ }^{a, b}$ Messoud Ashina ${ }^{a}$ Jacob P. Thyssen ${ }^{b}$ \\ Alexander Egeberg ${ }^{b}$ \\ aDanish Headache Center, Department of Neurology, Rigshospitalet Glostrup, \\ Glostrup, Denmark; ${ }^{b}$ Department of Dermatology, Bispebjerg Hospital, \\ Copenhagen, Denmark
}

\section{Keywords}

Flushing $\cdot$ Rifaximin $\cdot$ Rosacea $\cdot$ Sumatriptan

\begin{abstract}
We present 2 cases of rosacea that were successfully managed with off-label treatment. The first is a case of painful, exuding papulopustular lesions of the nose treated with rifaximin, and the other is a case of severe, debilitating and painful flushing treated with sumatriptan. The cases support previous notions that gastrointestinal comorbidities may be related to papulopustular lesions and that flushing may be related to neurogenic inflammation and migraine. The cases also imply that a new approach to rosacea management, based on endotypes and comorbidities, may be warranted.

(C) 2021 The Author(s)

Published by S. Karger AG, Basel
\end{abstract}

\section{Introduction}

The rosacea umbrella comprises various clinical manifestations which may act alone or in concert, including facial erythema, papules/pustules, phymatous changes, and ocular

Alexander Egeberg
Department of Dermatology, Bispebjerg Hospital
Nielsine Nielsens Vej 9
DK-2400 Copenhagen (Denmark)
alexander.egeberg@gmail.com




\section{Case Reports in Dermatology}

Case Rep Dermatol 2021;13:121-128

DOI: $10.1159 / 000511984$

(c) 2021 The Author(s). Published by S. Karger AG, Basel www.karger.com/cde

Wienholtz et al.: Subtype-Specific Off-Label Treatment of Rosacea

symptoms. The disease is difficult to effectively manage, few rosacea-specific treatments exist, and off-label treatment is often warranted. We have listed some of the most recently suggested off-label treatments for rosacea in Table 1 and Table 2 (for references for Table 1 and Table 2, see online suppl. material; www.karger.com/doi/10.1159/000511984). Rosacea has been associated with a number of comorbidities. Some comorbidities appear to be related to specific subtypes, e.g., papulopustular subtype to gastrointestinal comorbidities [1], and erythematotelangiectatic rosacea (ETR) and ocular rosacea to neurological disease [2,3]. We here present 2 cases of rosacea that were effectively managed according to this concept with off-label treatment of their symptoms with nonrosacea medication.

\section{Case Presentation}

The first case is a 46-year-old male presenting with an acute flare-up of painful, exuding papulopustular lesions primarily affecting the nose. Lesions were associated with itching, stinging and increased nasal skin sensitivity. He was diagnosed with rosacea 10 years before, predominantly of the papulopustular subtype. He had been treated with topical metronidazole on/off for 4 years, and later with low-dose oral isotretinoin with some effect. Since 2017, he had used topical azelaic acid and topical metronidazole for recurring lesions. Due to increased skin sensitivity in the current flare-up, azelaic acid was painful. As the patient wanted to avoid long-lasting antibiotic treatment with doxycycline, we decided to try oral rifaximin $200 \mathrm{mg} 3$ times a day for 3 days in addition to his current maintenance therapy (topical metronidazole twice daily). Five days after initiating rifaximin, exudation was stopped, lesions healed, and the nose felt less swollen (Fig. 1). Discrete subjective skin tightness and dryness remained but could be relieved with continued use of topical metronidazole.

The second case is a 52-year-old female known with ETR. She experienced recurrent painful and disabling flares of flushing (erythema, edema, and severe burning sensation) lasting for days or sometimes weeks. Flares were associated with photosensitivity and a general feeling of discomfort/illness. These flares share some likeness with the neurological disorder, migraine, which has previously been shown to be associated with rosacea [3, 4]. The patient reported that she rarely had headache and had never had a migraine. For the flare-ups, she had previously tried topical metronidazole and brimonidine tartrate with some effect on chronic erythema, but not on the flares. We administered oral sumatriptan $(50 \mathrm{mg}$ ) for the flares resulting in a significant reduction of burning, edema, erythema, and pain 30-60 min after intake (Fig. 2). Symptoms did not recur in the days following treatment. The patient tried oral sumatriptan on several flare occasions with sustained efficacy.

\section{Discussion}

As illustrated in the present cases, the pathophysiology behind rosacea seems to be multifactorial, involving cathelicidin and inflammasome-associated pathways for papules and

\section{Karger's}




\section{Case Reports in Dermatology}

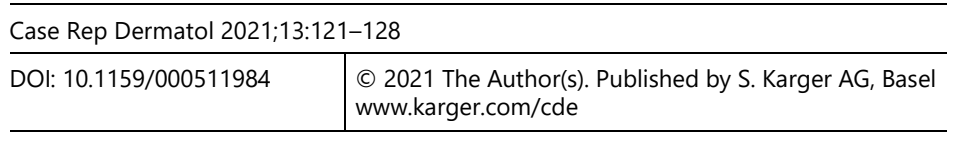

Wienholtz et al.: Subtype-Specific Off-Label Treatment of Rosacea

pustules $[5,6]$, whereas neurogenic inflammation with release of vasoactive neuropeptides, such as calcitonin gene-related peptide (CGRP), may be more prominent in ETR [6].

Gastrointestinal comorbidities, such as small intestinal bacterial overgrowth (SIBO) [1, 7, 8], Helicobacter pylori infection [8,9], and irritable bowel syndrome, are common in rosacea [8]. SIBO may lead to circulating cytokines which can trigger rosacea $[7,10]$, and interestingly, eradication of SIBO with rifaximin has been shown to improve papulopustular symptoms in more than half of rosacea patients, possibly due to either an effect on gut bacteria, regulation of the immune system, or anti-inflammatory activity $[1,11]$. Rifaximin is currently undergoing clinical testing in rosacea (ClinicalTrials.gov NCT03864978).

Rosacea has been consistently linked with migraine in observational studies [3, 4]. It is unclear exactly how migraine and rosacea are linked, but they are suggested to share common pathophysiologic pathways [12]. The signaling neuropeptide CGRP has been widely investigated in relation to migraine and is known to induce vasodilation and neurogenic inflammation [13]. Interestingly, infusion of CGRP in patients with migraine induces flushing and can trigger migraine attacks [14]. The anti-migraine drug sumatriptan has been found to block release of CGRP [15], which may explain the effect in the presented case.

\section{Conclusion}

It seems that rosacea should not be regarded as one homogenous disease, but that subtypes under the umbrella may in fact represent endotypes with different pathophysiologic pathways related to different organ systems, i.e., gut or brain. Thus, endotypes with related comorbidities may be considered for a more effective management of rosacea in the future.

\section{Statement of Ethics}

The authors have no ethical conflicts to disclose. The patients gave written informed consent for publication of their cases (including publication of images). The study was conducted in accordance with the Helsinki II Declaration of 1964, with revisions until the Brazil conference in 2013.

\section{Conflict of Interest Statement}

The authors have no conflicts of interest to declare in relation to these cases.

\section{Funding Sources}

None.

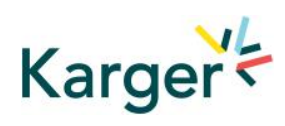




\section{Case Reports in Dermatology}

Case Rep Dermatol 2021;13:121-128

DOI: $10.1159 / 000511984$

(C) 2021 The Author(s). Published by S. Karger AG, Basel www.karger.com/cde

Wienholtz et al.: Subtype-Specific Off-Label Treatment of Rosacea

\section{Author Contributions}

Dr. Wienholtz contributed to conception, design, interpretation, and manuscript preparation. Dr. Ashina contributed to acquisition, design, interpretation, and manuscript preparation. Dr. Thyssen contributed to conception, design, interpretation, and manuscript preparation. Dr. Egeberg contributed to acquisition, conception, design, interpretation, and manuscript preparation. All authors read and approved the final manuscript.

\section{References}

1 Drago F, De Col E, Agnoletti AF, Schiavetti I, Savarino V, Rebora A, et al. The role of small intestinal bacterial overgrowth in rosacea: A 3-year follow-up. J Am Acad Dermatol. 2016 Sep;75(3):e113-5.

2 Egeberg A, Hansen PR, Gislason GH, Thyssen JP. Association of rosacea with risk for glioma in a danish nationwide cohort study. JAMA Dermatol. 2016 May;152(5):541-5.

3 Egeberg A, Ashina M, Gaist D, Gislason GH, Thyssen JP. Prevalence and risk of migraine in patients with rosacea: A population-based cohort study. J Am Acad Dermatol. 2017 Mar;76(3):454-8.

4 Spoendlin J, Voegel JJ, Jick SS, Meier CR. Migraine, triptans, and the risk of developing rosacea: a populationbased study within the United Kingdom. J Am Acad Dermatol. 2013 Sep;69(3):399-406.

5 Steinhoff M, Schauber J, Leyden JJ. New insights into rosacea pathophysiology: a review of recent findings. J Am Acad Dermatol. 2013 Dec;69(6 Suppl 1):S15-26.

6 Holmes AD, Steinhoff M. Integrative concepts of rosacea pathophysiology, clinical presentation and new therapeutics. Exp Dermatol. 2017 Aug;26(8):659-67.

7 Parodi A, Paolino S, Greco A, Drago F, Mansi C, Rebora A, et al. Small intestinal bacterial overgrowth in rosacea: clinical effectiveness of its eradication. Clin Gastroenterol Hepatol. 2008 Jul;6(7):759-64.

8 Egeberg A, Weinstock LB, Thyssen EP, Gislason GH, Thyssen JP. Rosacea and gastrointestinal disorders: a population-based cohort study. Br J Dermatol. 2017 Jan;176(1):100-6.

9 Jørgensen AR, Egeberg A, Gideonsson R, Weinstock LB, Thyssen EP, Thyssen JP. Rosacea is associated with Helicobacter pylori: a systematic review and meta-analysis. J Eur Acad Dermatol Venereol. 2017 Dec;31(12):2010-5.

10 Weinstock LB. Rosacea in Crohn's Disease: effect of Rifaximin. J Clin Gastroenterol. 2011 Mar;45(3):295-6.

11 Vera N, Patel NU, Seminario-Vidal L. Rosacea Comorbidities. Dermatol Clin. 2018 Apr;36(2):115-22.

12 Christensen CE, Andersen FS, Wienholtz N, Egeberg A, Thyssen JP, Ashina M. The relationship between migraine and rosacea: systematic review and meta-analysis. Cephalalgia. 2017 Sep;38(7):033310241773177.

13 Buzzi MG, Bonamini M, Moskowitz MA. Neurogenic model of migraine. Cephalalgia. 1995;15(4):277-80.

14 Guo S, Vollesen AL, Olesen J, Ashina M. Premonitory and nonheadache symptoms induced by CGRP and PACAP38 in patients with migraine. Pain. 2016 Dec;157(12):2773-81.

15 Goadsby PJ, Edvinsson L. The trigeminovascular system and migraine: studies characterizing cerebrovascular and neuropeptide changes seen in humans and cats. Ann Neurol. 1993 Jan;33(1):48-56. 


\section{Case Reports in Dermatology}
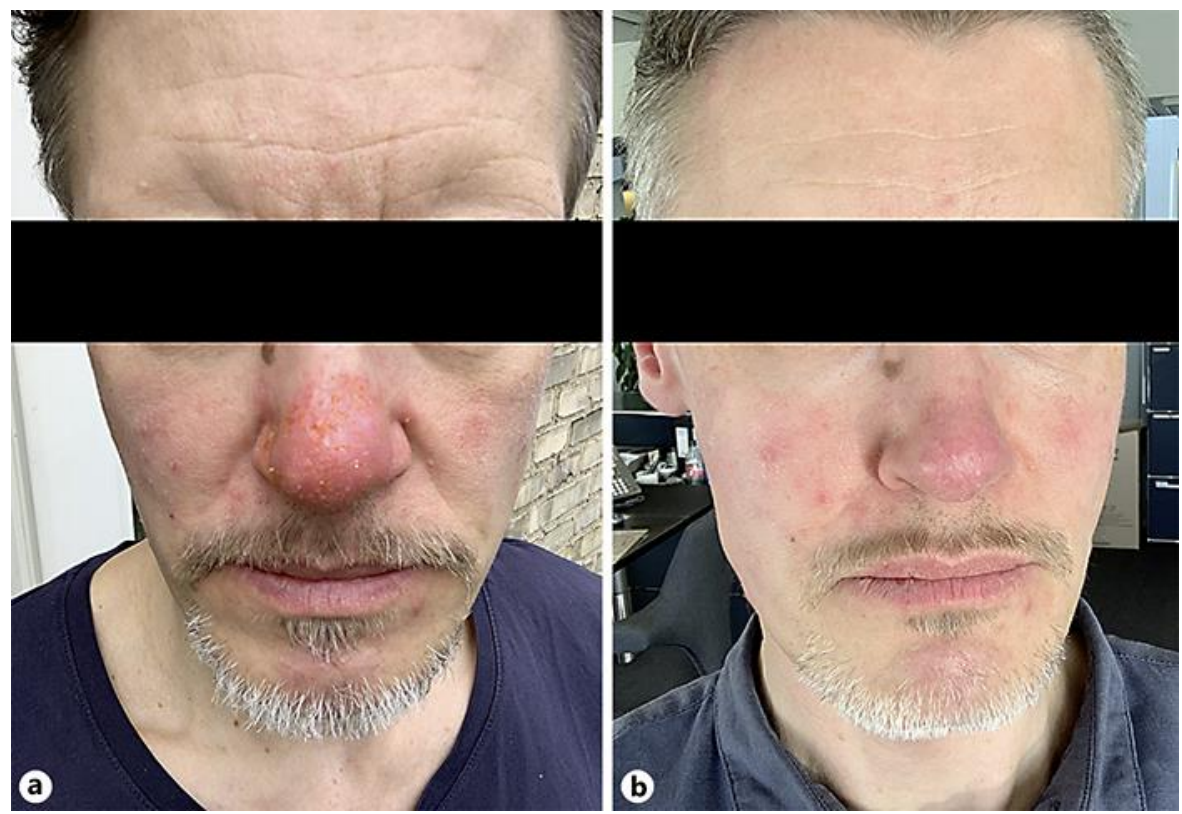

Fig. 1. A 46-year-old male treated with oral rifaximin $200 \mathrm{mg} 3$ times a day for 3 days in combination with maintenance therapy of topical metronidazole twice daily. a Presentation immediately prior to initiation of rifaximin. b Presentation 5 days later. 


\section{Case Reports in Dermatology}
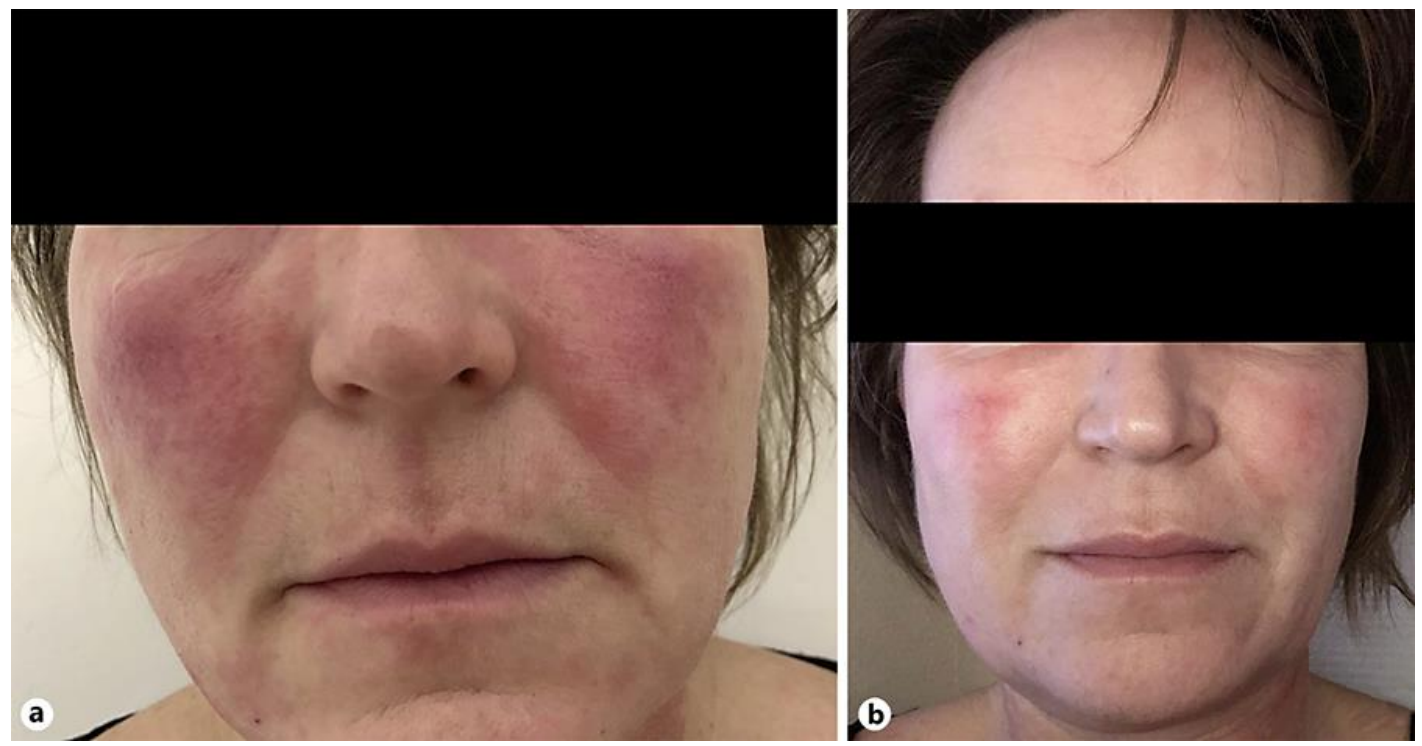

Fig. 2. A 52-year-old female with erythematotelangiectatic rosacea with flare-ups of severe flushing with edema and burning sensation lasting on average 2-3 days. a Presentation during a flare-up. b Presentation $60 \mathrm{~min}$ after intake of oral sumatriptan $50 \mathrm{mg}$. 
Table 1. Overview of off-label treatments suggested for rosacea in recent literature ${ }^{a}$

\begin{tabular}{|c|c|c|}
\hline Management option & Subtype & $\begin{array}{l}\text { Quality of } \\
\text { Evidence }^{\mathrm{b}}\end{array}$ \\
\hline \multicolumn{3}{|l|}{ Topical } \\
\hline Artemether emulsion [1] & PPR & $\mathrm{C}$ \\
\hline Crotamiton [2] & ETR & $\mathrm{C}$ \\
\hline (+ benzyl benzoate) [3] & PPR & \\
\hline Dapsone gel $5 \%[4,5]$ & PPR & $\mathrm{C}$ \\
\hline 1\% 4-ethoxybenzaldehyde & ETR & $\mathrm{C}$ \\
\hline Gluthathione-C4 (0.1\%), beta-glycyrrhetinic (0.5\%), and azelaic acid (10\%) [6] & & $\mathrm{C}$ \\
\hline \multirow[t]{2}{*}{ Honevo (Kanuka Honey) [7] } & ETR & $\mathrm{C}$ \\
\hline & PPR & \\
\hline Hydroxypropyl chitosan and potassium azeloyl diglycinate (5\%) [8] & ETR & $\mathrm{C}$ \\
\hline \multirow[t]{2}{*}{ Liposomal polyvinylpyrrolidone-iodine hydrogel [9] } & ETR & $\mathrm{C}$ \\
\hline & PPR & \\
\hline Liposomal sodium copper chlorophyllin complex [10] & ETR & $\mathrm{C}$ \\
\hline \multirow[t]{2}{*}{ 1-Methylnicotinamide [11] } & ETR & $\mathrm{C}$ \\
\hline & PPR & \\
\hline \multirow[t]{2}{*}{ Permethrin gel [12-14] } & ETR & $\mathrm{B}$ \\
\hline & PPR & \\
\hline \multirow[t]{2}{*}{ Pimecrolimus 1\%c [15-19] } & ETR & B \\
\hline & PPR & \\
\hline \multirow[t]{2}{*}{ Praziquantel [20] } & ETR & $\mathrm{C}$ \\
\hline & PPR & \\
\hline Serine protease inhibitor [21] & PPR & $\mathrm{C}$ \\
\hline Tacrolimus $0.1 \%$ c [22] & ETR & $\mathrm{C}$ \\
\hline \multirow{2}{*}{ Timolol maleate $0.5 \%[23]$} & ETR & $\mathrm{C}$ \\
\hline & PPR & \\
\hline Tranexamic acid [24-27] & ETR & $\mathrm{C}$ \\
\hline \multicolumn{3}{|l|}{ Oral } \\
\hline \multirow[t]{2}{*}{ Phosphodiesterase type 4 inhibitor (apremilast) [28] } & ETR & $\mathrm{C}$ \\
\hline & PPR & \\
\hline \multirow{3}{*}{$\begin{array}{l}\text { Escherichia coli Nissle } 1917 \text { + regular topical therapy for rosacea [29] } \\
\text { Hydroxychloroquine }[30,31]\end{array}$} & PPR & $\mathrm{C}$ \\
\hline & ETR & $\mathrm{C}$ \\
\hline & PPR & \\
\hline Rifaximin [32-37] & PPR & $\mathrm{B}$ \\
\hline \multirow{2}{*}{$\begin{array}{l}\text { Thalidomide [38] } \\
\text { (+ pimecrolimus) [19] }\end{array}$} & ETR & $\mathrm{C}$ \\
\hline & PPR & \\
\hline Turmeric polyherbal formulation [39] & ETR & $\mathrm{C}$ \\
\hline
\end{tabular}




\section{Case Reports in Dermatology}

Case Rep Dermatol 2021;13:121-128

DOI: $10.1159 / 00051198$

2021 The Author(s). Published by S. Karger AG, Basel www.karger.com/cde

Wienholtz et al.: Subtype-Specific Off-Label Treatment of Rosacea

Table 2. Overview of off-label treatments suggested for rosacea in recent literature ${ }^{\text {a }}$ (continued)

\begin{tabular}{|c|c|c|}
\hline Management option & Subtype & $\begin{array}{l}\text { Quality of } \\
\text { Evidence }^{b}\end{array}$ \\
\hline $\begin{array}{l}\text { Devices and surgical interventions } \\
\text { (Abo/Inco) Botulinumtoxin A [40-44] }\end{array}$ & ETR & $\mathrm{B}$ \\
\hline Dual-frequency ultrasound [45] & $\begin{array}{l}\text { ETR } \\
\text { PPR }\end{array}$ & $\mathrm{C}$ \\
\hline Coupled blue and red light-emitting diodes therapy [46] & PPR & $\mathrm{C}$ \\
\hline Interleukin-17 blockade [47] & PPR & $\mathrm{C}$ \\
\hline Long-pulsed 1,064-nm neodynium:yttrium-aluminum-garnet laser [48] & PPR & $\mathrm{C}$ \\
\hline Microfocused ultrasound [49] & ETR & $\mathrm{C}$ \\
\hline Microneedling radiofrequency [50] & ETR & $\mathrm{C}$ \\
\hline Photodynamic therapy + (methyl) aminolevulinate $[51,52]$ & $\begin{array}{l}\text { ETR } \\
\text { PPR }\end{array}$ & $\mathrm{C}$ \\
\hline
\end{tabular}

PPR, papulopustular rosacea; ETR, erythematotelangiectatic rosacea. a Table with references is available as online supplementary material. ${ }^{b}$ Quality of evidence (A, B, or C): A: Randomized controlled trials; B: Systematic review/metaanalysis of lower-quality clinical trials or studies with limitations and inconsistent findings; lower-quality clinical trial; cohort study; case-control study; C: Consensus guidelines; usual practice; expert opinion; case series; limited trial data. c May also cause rosacea-like eruption in the face. 